\title{
Changing Trends in Ritual Attendance and Spirituality throughout the College Years
}

\author{
Chelsi A. Creech, Paul J. Handal, Sean A. Worley, Travis J. Pashak, \\ Eunice J. Perez, Lea Caver \\ Saint Louis University, St Louis, USA \\ Email: handalpj@slu.edu
}

Received October $8^{\text {th }}, 2013$; revised November $7^{\text {th }}, 2013$; accepted November $29^{\text {th }}, 2013$

\begin{abstract}
Copyright (C) 2013 Chelsi A. Creech et al. This is an open access article distributed under the Creative Commons Attribution License, which permits unrestricted use, distribution, and reproduction in any medium, provided the original work is properly cited. In accordance of the Creative Commons Attribution License all Copyrights $\mathbb{C}$ 2013 are reserved for SCIRP and the owner of the intellectual property Chelsi A. Creech et al. All Copyright $\mathbb{C}$ 2013 are guarded by law and by SCIRP as a guardian.
\end{abstract}

\begin{abstract}
According to previous literature, levels of religiousness decrease among emerging adults, but similar research has not been done regarding levels of spirituality. The current study examined the responses of college students to measures of religiousness and spirituality. The participants in the study were from a private, religiously affiliated university in the Midwest, between ages 18 and 24. Participants completed the Personal Religious Inventory (PRI), the Duke Religion Index (DUREL), the Spiritual Transcendence Scale (STS), the Daily Spiritual Experiences Scale (DSES) and the Spiritual Involvement and Beliefs Scale (SIBS). Significant differences were found between first-year and upper-class participants on religious attendance, non-religious attendance, and the Daily Spiritual Experiences Scale. Based on these results, it is suggested that multi-dimensional measures provide a more accurate view of religiousness than one-dimensional measures.
\end{abstract}

Keywords: Religion; Spirituality; College Students

\section{Introduction}

Until the 1960s, religiousness and spirituality were not considered as separate belief systems (Hood Jr., Hill, \& Spilka, 2009). For this reason, religion and spirituality were not researched as separate constructs until more recently (Zinnbauer et al., 1997). In the last fifteen years, a body of research has developed regarding the differences between the two constructs, but the constructs are operationalized in almost as many different ways as there are studies (Zinnbauer et al., 1997). In a 1993 study, Gorsuch suggested the following definitions: spirituality encompasses a person's beliefs, values, and behavior, whereas religiousness is a personal involvement in a specific religious institution and traditions (Hood Jr. et al., 2009). Some researchers, however, suggest that there is no such thing as spirituality outside of institutional religion (Hood Jr. et al., 2009). Other studies, such as Zinnbauer et al. (1997), show a frequent interchanging of the two terms, despite attempting to highlight differences between them.

In their textbook on the subject, Hood Jr. et al. (2009) highlighted five key characteristics they say to separate the two constructs. Spirituality is personal and subjective, without an institutional or organized structure, and with high importance placed on commitments to personal values. It may not include a deity. Religiousness, by this definition, is a type of spirituality. It always involves spirituality and is objective, institutional and creedal, but spirituality need not always include religiousness. This confusion about the definitions has made concrete distinctions difficult to come by, but what has been clear is the grow- ing trend in American culture to identify as spiritual and not religious, when participants are asked to self-identify. Most recently, in 2010 the Pew Research on Religion and Public Life Project (PEW), it is found that around $30 \%$ of the American public would self-identify as "spiritual but not religious". The 2012 PEW poll found that $20 \%$ of Americans do not claim any religious affiliation. Based on these numbers, it seems clear that people in general feel there is a difference between the two terms, despite difficulties in researching such differences.

Supporting the notion that religiousness may be a subset of spirituality, Kneipp, Kelly and Cyphers (2009) found that high scores on the Spiritual Well Being scale accounted for $16 \%$ of the differences between students on the Student Adaptation to College Questionnaire. Religiousness, measured by the Religiousness Measure/Demographic Questionnaire, only accounted for another $6 \%$ of the variance between the students. Along with suggesting that there is some overlap between the two constructs, this study also showed the importance of spirituality and religiousness in college adjustment. Those with higher scores on the spirituality and religiousness scales also generally had higher scores on the measure of college adjustment. However, this study looked only at the levels of spirituality and religiousness in the first year of college and did not track the changes that may occur throughout the college years.

Evidence suggests that levels of religiousness decrease throughout the college years (Uecker, Regnerus, \& Vaaler, 2007; Astin, Astin, \& Lindholm, 2011; Scheitle, 2011). However, Lee (2002) reported a decrease in ritual attendance during 
college, and also reported an increase in religious conviction across the college years. This finding is of importance because it focuses on what aspect of religion is measured in studies concerned with an increase or decrease in religion during the college years. Apparently, the issue of measurement originated in the early studies of religion which equated a decrease in ritual attendance with a decrease in religious belief (Feldman, 1968). More recently, Uecker et al. (2007) found that college students' religious convictions decreased less than their non-college attending peers. Based on this result, they posited that it was not a decrease in belief that changed, but rather only religious attendance.

Contradictory results were reported by Astin et al. (2011) who analyzed data from the Higher Education Research Institute's Spirituality in Higher Education project. Their results showed that students who self-identified as Christian as first year students and attended Evangelical-affiliated schools showed an increase in overall religiousness throughout college, but Christian students at schools of other affiliations or secular institutions decreased in religiousness, as measured by the Religious Tradition measure (RELTRAD). Students who selfidentified as members of a minority religion (e.g., Buddhism, Islam, Judaism) and attended an Evangelical affiliated school decreased in religiousness. Catholic and secular institutions showed equal rates of decline in religiousness among all students. At the Catholic institutions, this was equally true of the Catholic students as well as those not affiliated with the Catholic religion.

The literature is unclear about the relationship between religion and the college years. The literature shows a decrease in religion, but it is unclear what is really decreasing-is it religious belief, conviction, or religious attendance? These discrepancies seem to be a problem of measurement, namely what is being measured; is it ritual attendance, or religious attendance, or religious beliefs or religious convictions. Additionally, it is notable that there is little research investigating the spirituality during the college years.

The present study investigated the relationship between religion and the college years by using a multi-dimensional measure of religiousness, which assessed ritual attendance, non-ritual attendance, and religious beliefs and practices. Additionally, this study investigated the relationship between spirituality and the college years by using three measures of spirituality, the Daily Spiritual Experiences Scale (DSES), the Spiritual Transcendence Scale (STS), and the Spiritual Involvement and Beliefs Scale (SIBS).

\section{Method}

\section{Participants}

Participants were 280 undergraduate students from a private Midwestern university. The study included students between the ages of 18 and $24(M=19.91, S D=3.47)$. Of the 280,190 were female $(66 \%)$ and 196 were Caucasian $(69 \%)$. There were 147 Catholics (52\%), 56 other Christians (20\%), 29 were atheist or agnostic $(9 \%), 15$ were Hindus $(5 \%), 6$ were Muslims $(2 \%)$, and 25 were some other religion ( $9 \%)$. Two participants chose not to report their religious affiliation. Freshmen or first year students numbered $169(60 \%)$ of the sample. Sophomore participants numbered 52 (19\%). Juniors numbered 42 (15\%), and seniors numbered $15(5 \%)$. Because of the small $\mathrm{N}$ of jun- iors and seniors, they were combined for analysis, for an $\mathrm{N}$ of 57 (20\%).

\section{Measures}

\section{Spirituality Measures}

The 2004 Daily Spiritual Experiences Scale (DSES) is measured by a 16-item index. Participants were asked to indicate how often they have certain spiritual experiences. The responses range from never (coded 1), to many a day (coded 6). Items were coded in the direction that higher scores reflected a greater level of daily spiritual experiences $(a=.96)$. Scores were summed for each respondent and then averaged across the 16 items. One of these items ("In general, how close do you feel to God?") is reverse scored in a 4-point metric (not at all, somewhat close, very close, as close as possible) instead of a 6-point likert scale. To be consistent with the directionality (Underwood, 2002), the raw score of this item is reversed coded and the 4-point scale is adjusted to fit the 6-point spectrum. The adjusted score is averaged for this subscale into the total for the resulting mean score. Further, the scale was divided into two subscales: a "theistic" subscale, with an alpha reliability of .95 and a "hon-theistic (self-transcendent)" subscale, with an alpha reliability of .90 (Ellison \& Fan, 2007).

The Spiritual Transcendence Scale (STS) is a 24-item scale, developed by Piedmont (2009), which consists of three subscales: universality, prayer fulfillment, and connectedness. Universality is the belief in the unity and purpose of life, prayer fulfillment is a feeling of joy and contentment that results from prayer or meditation, and connectedness is a sense of personal responsibility and connection to others. The scale items were answered on a 1 (strongly agree) to 5 (strongly disagree) likerttype scale. Piedmont (2009) showed these scales to have acceptable reliabilities for the subscales: .83 for universality, .87 for prayer fulfillment, and .64 for connectedness (Akyalcin, Greenway, \& Milne, 2008).

The Spiritual Involvement and Beliefs Scale (SIBS) (Hatch et al., 1998) was designed to measure participants' spiritual status. It consists of four sub-scales. The first is the external/ ritual scale, which is a 13-item scale that reflects belief in a greater power. Second is the internal/fluid scale, with 11 items that reflect internal beliefs and growth. The third is the existential/meditative subscale, seven items which reflect existential issues. Finally is the humility/personal application subscale with four items that reflect humility and application of spiritual principles. Internal reliability statistics for three of the subscales are satisfactory: external/ritual, $\alpha=.98$; internal/fluid, $\alpha=.74$; existential/meditative, $\alpha=.70$ ) but perhaps, as Hatch et al. (1998) suggest, not for humility/personal application sub-scale $(\alpha=.51)$. The internal consistency of the SIBS was reportedly high (Cronbach's alpha $=.92)$ and presented a test-retest reliability of $r=.92$. This scale strengthens measures of spirituality by evading the usage of cultural-religious bias, and assessment of beliefs and actions (Maltby \& Day, 2001).

\section{Religiousness Measures}

The PRI (Lipsmeyer, 1984) is a 45-item, nine scale, multidimensional measure of religiosity. The scales measure personal prayer (PRP); ritual attendance (RA); non-ritual, churchrelated activity (NRA); belief in God (BLFGOD); belief in an afterlife (AFTLIFE); perceived congruence of a person's reli- 
gious beliefs with their attitudes on social and moral issues (RSM); the extent to which an individual's ideas about religion guide their philosophy or way of life (IDEO); the subjective experience of feeling close to God (CLOSEGOD); and integration or the extent to which persons perceive that their relationship with God influences their cognition, affect, and behavior (INT). Most of the items use a 6-point Likert response format; however, others use a multiple-choice or yes/no format.

According to Lipsmeyer, test-retest reliability coefficients over a one-week period were between .83 and .97 for the nine scales in an adult population. Additionally, Lipsmeyer found that the PRI had high concurrent validity; religious professionals (e.g., priests, ministers, nuns) scored significantly higher on all scales than the general public. Also, Lipsmeyer reported that atheists, agnostics, and those with no religious preference scored significantly lower than other major religious groups. Lipsmeyer reported that each subscale of the PRI correlated highest with integration (INT), and that it had the highest stability coefficient and was the best single measure of religion (Ross, Handal, Clark, \& Vander Wal, 2009).

The Duke University Religion Index (DUREL) is a five-item measure of religious involvement that is incorporated in epidemiological surveys inspecting the affiliation between religion and health outcomes (Koenig \& Bussing, 2010). This brief measure of religiosity was established for use in both crosssectional and longitudinal studies. It evaluates three main dimensions of religiosity: organizational religious activity, nonorganizational religious activity, and intrinsic/subjective religiosity. The scale assesses each of these components by a separate "subscale", and correspondences between health outcomes should be examined by subscale in different models. The scale as a whole displayed high test-retest reliability (intra-class correlation $=.91$ ), high internal consistence (Cronbach's alpha's $=.78-.91)$ and has high convergent validity with other religiosity measures (r's $=.71-.86)$.

\section{Demographic Measure}

The participants also completed a 22-item demographic questionnaire. These items asked about a participant's age, ethnicity, sex, religious affiliation, college living arrangement, volunteer and work positions, and finally whether a participant identified as spiritual, religious or both.

\section{Procedure}

Participants were recruited from undergraduate psychology classes. Some classes (approximately 66\%) offered class credit for participation, while the other classes were not offered incentives for participation. Participants accessed the study via SONA, a university-approved research recruitment program, or through a link provided to them by professors who helped with recruitment. After accessing the study, they were directed to a link to the Qualtrics site that was hosting the survey. Participants first answered the demographic questionnaire. Next, the participants progressed through the Duke University Religious Index, the Personal Religious Inventory, the Daily Spiritual Experience Scale, the Spiritual Transcendence Scale, and the Spiritual Involvement and Beliefs Scale. Participants were encouraged to complete all sections in order, but were able to progress through the questionnaires at will. Participants were able to end the survey at any time, and were able to skip any questions they chose.

\section{Results}

In order to determine whether significant differences existed on the measures on religion and spirituality, a series of analyses of variance were computed and for significant F-values, follow up Tukey's HSD were computed to determine differences between groups. Results of these analyses revealed that significant differences existed on measures of ritual attendance $(F(2$, $286)=5.09, p<.007)$, non-ritual attendance $(F(2,286)=3.63$, $p<.027)$, and the Daily Spiritual Experiences Scale $(F(2,286)$ $=4.88, p<.008)$. No significant differences were found on the other religion and spirituality measures.

Results for Ritual attendance revealed that first year students reported significantly higher levels of Ritual attendance (RA) $(M=13.04, S D=5.13)$ than upper-class students $(M=11.28$, $S D=5.55, p<.01)$. There were no significant differences between the sophomore participants and either the first-year or the upper-class participants, with regard to ritual attendance.

Results for Non-Ritual attendance (NRA) revealed that, first year participants reported significantly higher levels of NRA $(M=10.65, S D=4.59)$ than upper-class participants $(M=9.27$, $S D=4.56, p<.01)$. There were no significant differences between the sophomore participants and either the first year or the upper-class participants, with regard to religious attendance.

Finally, first year participants reported significantly higher scores on the Daily Spiritual Experiences Scale $(M=57.73, S D$ $=16.54)$ than upper-class participants $(M=51.56, S D=18.56$, $p<.009)$. There were no significant differences between the sophomore participants and either the first year or the upperclass participants, with regard to religious attendance.

\section{Discussion}

The results of this study, namely that ritual attendance and non-ritual attendance decreases during college, support the findings reported by Lee (2002) and extend them in terms of our finding that non-ritual attendance also decreases during college. This later finding is not surprising since it may be expected that attendance at non-ritual church events would decrease because college students appear to be decreasing their attendance at ritual events.

It is notable that no significant differences were reported for the DUREL measure, which is a measure of religion. It is likely that differences were found with the PRI and not with the DUREL because the PRI is a multi-dimensional measure, with separate scales for each of nine dimensions, whereas the DUREL, although it has one item that asks about church attendance, consists of a total score, which precludes a sensitivity to the specific area of ritual and non-ritual attendance.

Additional results revealed that spirituality, as measured by the DSES, decreased during the college years. However, this finding did not occur on the other measures of spirituality, namely the STS and the SIBS. It is possible that these results are due to the fact that the DSES purports to measure how often certain spiritual experiences occur, while the other two scales purport to measure beliefs in unity, contentment, a greater power and other internal beliefs. It may be that the DSES is more experiential and the other measures are more cognitive. These results are intriguing and certainly require additional research. 
This study reflects the existence of an ongoing difficulty in research in the area of religion and spirituality, namely the difficulty that exists in measuring the constructs of religion and spirituality. Contradictory findings may be explained by the difference in the measures employed in a particular study as operation definitions of the constructs of religion and spirituality.

Our results were found with a relatively small sample, which would lend itself to a Type II error. It would be important that additional research occur with a larger sample across each year level to replicate our findings and to determine whether a Type II error occurred on the other measures of spirituality.

\section{REFERENCES}

Akyalcin, E., Greenway, P., \& Milne, L. (2008). Measuring transcendence: Extracting core constructs. The Journal of Transpersonal Psychology, 40, 41-59.

Astin, A. W., Astin, H. A., \& Lindholm, J. A. (2011). Assessing students' spiritual and religious qualities. Journal of College Student Development, 52, 39-61. http://dx.doi.org/10.1353/csd.2011.0009

Ellison, C. G., \& Fan, D. (2008). Daily spiritual experiences and psychological well-being among US adults. Social Indicators Research, 88, 247-271. http://dx.doi.org/10.1007/s11205-007-9187-2

Feldman, K. (1968). Change and stability of religious orientations during college: Part I. freshman-senior comparisons. Review of Religious Research, 11, 40-60. http://dx.doi.org/10.2307/3510552

Hatch, R. L., Burg, M. A., Naberhaus, D. S., \& Hellmich, L. K. (1998). The Spiritual Involvement and Beliefs Scale: Development and testing of a new instrument. The Journal of Family Practice, 46, 476486.

Hood Jr., R., Hill, P., \& Spilka, B. (2009). The psychology of religion. (4th ed.). New York: The Guilford Press.

Koenig, H. G., \& Bussing, A. (2010). The Duke University Religion Index (DUREL): A five-item measure for use in epidemiological studies. Religions, 1, 78-85. http://dx.doi.org/10.3390/rel1010078

Kneipp, L. B., Kelly, K. E., \& Cyphers, B. (2009). Feeling at peace with college: Religiosity, spiritual well-being, and college adjustment.
Individual Differences Research, 7, 188-196.

Lee, J. J. (2002). Religion and college attendance: Change among students. The Review of Higher Education, 25, 369-384. http://dx.doi.org/10.1353/rhe.2002.0020

Lipsmeyer, M. E. (1984). The measurement of religiosity and its relationship to mental health/impairment. Unpublished Doctoral Dissertation, St. Louis, MO: Saint Louis University.

Maltby, J., \& Day, L. (2001). Spiritual involvement and belief: The relationship between spirituality and Eysenck's personality dimensions. Personality and Individual Differences, 30, 187-192. http://dx.doi.org/10.1016/S0191-8869(00)00024-6

PEWResearch (2012). Religion and the unaffliated. http://www.pewforum.org/2012/10/09/nones-on-the-rise-religion/

Piedmont, R. L., Ciarrochi, J. W., Dy-Liacco, G. S., \& Williams, J. G. (2009). The empirical and conceptual value of the spiritual transcendence and religious involvement scales for personality research. Psychology of Religion and Spirituality, 1, 162-179. http://dx.doi.org/10.1037/a0015883

Ross, K., Handal, P., Clark, E., \& Vander Wal, J. (2009). The relationship between religion and religious coping: Religious coping as a moderator between religion and adjustment. Journal of Religion and Health, 48, 454-467. http://dx.doi.org/10.1007/s10943-008-9199-5

Scheitle, C. P. (2011). Religious and spiritual change in college: Assessing the effect of a science education. Sociology of Education, 84, 122-136. http://dx.doi.org/10.1177/0038040711401811

Uecker, J. E., Regnerus, M. D., \& Vaaler, M. L. (2007). Losing my religion: The social sources of religious decline in early adulthood. Social Forces, 85, 1667-1687. http://dx.doi.org/10.1353/sof.2007.0083

Underwood, L. G., \& Teresi, J. T. (2002). The Daily Spiritual Experience Scale: Development, theoretical description, reliability, exploratory factor analysis, and preliminary construct validity using health-related data. Annals of Behavioral Medicine, 24, 22-31. http://dx.doi.org/10.1207/S15324796ABM2401 04

Zinnbauer, B. J., Pargament, K. I., Cole, B., Rye, M. S., Butter, E. M., Belavich, T. G., Hipp, K. M., \& Scott, A. B. (1997). Religion and spirituality: Unfuzzying the fuzzy. Journal for the Scientific Study of Religion, 36, 549-564. http://dx.doi.org/10.2307/1387689 